\title{
The Coevolution of Networks and Political Attitudes
}

\author{
DAVID LAZER, BRIAN RUBINEAU, \\ CAROL CHETKOVICH, NANCY KATZ, and MICHAEL NEBLO
}

\begin{abstract}
How do attitudes and social affiliations coevolve? A long stream of research has focused on the relationship between attitudes and social affiliations. However, in most of this research the causal relationship between views and affiliations is difficult to discern definitively: Do people influence each other's views so that they converge over time or do they primarily affiliate (by choice or happenstance) with those of similar views? Here we use longitudinal attitudinal and whole network data collected at critical times (notably, at the inception of the system) to identify robustly the determinants of attitudes and affiliations. We find significant conformity tendencies: Individuals shift their political views toward the political views of their associates. This conformity is driven by social ties rather than task ties. We also find that political views are notably unimportant as a driver for the formation of relationships.
\end{abstract}

Keywords social network, social influence, homophily

How people simultaneously construct and are molded by their social milieu is one of the foundational questions of social science. In the study of politics, this was the central question of Lazarsfeld and collaborators (Lazarsfeld et al., 1948; Berelson, 1954), and in more recent years Huckfeldt, Sprague, and colleagues (Huckfeldt, Plutzer, \& Sprague, 1993; Huckfeldt \& Sprague, 1987, 1995; Huckfeldt, Johnson, \& Sprague 2002, 2004). The development of people's attitudes and their networks is a coevolutionary, dynamic process (Lazer, 2001). Views shape networks at the same time that networks shape views. This recursive evolution is a slippery subject for research, because in cross-sectional data it is difficult to disentangle the two processes of change. People who talk with each other may tend to become more similar in attitudes over time, but individuals also seek similar others to talk with.

This coevolutionary dynamic, we would argue, following Mutz (2002), Mansbridge (1999), and Huckfeldt, Johnson, and Sprague (2004), constitutes the very flesh and blood of the body politic: the multitude of little interactions and discussions that collectively represent popular deliberation about the issues of the day. Indeed, the mechanisms and quality of political opinion formation constitute the heart of democracy (Habermas, 1996). Therefore, it is important that we understand, for a given set of opportunities to interact

David Lazer is Associate Professor in the Department of Political Science at Northeastern University and Visiting Scholar at Harvard University. Brian Rubineau is Assistant Professor in the IRL School Department of Organizational Behavior at Cornell University. Carol Chetkovich is Professor in the Public Policy Program at Mills College. Nancy Katz is currently unaffiliated. Michael Neblo is Assistant Professor in the Department of Political Science at The Ohio State University.

Address correspondence to David Lazer, Department of Political Science, Northeastern University, Boston, MA 02115. E-mail: d.lazer@neu.edu 
with others, to what extent do people associate with those holding views at odds with their own? Do such associations, in turn, have an impact on what people believe?

Our objective in this article is to examine these processes in a microcosm, taking advantage of a natural experiment that occurs in educational settings, where individuals with few preexisting ties to one another are placed together in a structured environment for an extended period of time. We collected whole network data and examined at the micro level how political attitudes and interpersonal relationships develop over time. These data allow us to address the following questions: Throwing a set of individuals together with few or no prior relationships, what predicts the structure of the emergent network? How does this network, in turn, push and pull the political views of its constitutive individuals?

Our approach represents a significant methodological advance. A standard critique of studies of network influence is that so-called "network effects" are really just epiphenomenal selection effects due to individuals' choosing each other on some sort of individual-level basis, and that there are almost surely omitted factors related to both attitudes and network ties. Our research design, by focusing on the whole network, with longitudinal data collected at the inception of the social system, greatly reduces the power of such a critique. With this design, we can assess and control for individual attitudes before they are plausibly subject to any social influences within the social system. Thus, we can observe and estimate both selection and influence processes distinctly.

\section{Social Selection and Social Influence}

Our approach also represents a significant advance on the conceptual level. There have been several robust threads of research on network formation and social influence within political science, sociology, and social psychology. Two key themes run through these literatures: homophily (the tendency for similar individuals to share ties) and social influence (the tendency for individuals who have ties to become more similar). Following Lazer (2001), we pull together these ideas into a unified framework of coevolution of individual and network, in which an individual (ego) seeks an accommodation between his or her views and the views of his or her discussion partners (alters), with a particular focus on political views. That accommodation may be achieved by choosing similar alters with whom to talk, by adjusting attitudes to be in alignment with those of alters, or by some combination of these processes (cf. balance theory; Heider, 1958; Newcomb, 1961).

\section{Network Formation: Homophily}

Following Verbrugge (1977), we conceive the emergence of social networks as a "meeting and mating" process. A variety of forces, both exogenous and endogenous, influence opportunities for people to meet and interact. These interactions create the opportunity for the formation of friendships or other forms of affiliation ("mating").

One such force is that of homophily - that social ties are more commonly shared by similar individuals than dissimilar individuals. Homophily is among the most robust findings in social science (for a thorough review, see McPherson, Smith-Lovin, \& Cook, 2001). For example, discussion partners are likely to be similar in age, race, religion (Marsden, 1987), and, most relevant to the present article, political preferences (e.g., Huckfeldt \& Sprague, 1995; Ikeda \& Huckfeldt, 2001; Donatella et al., 2008). This similarity is partly the result of an opportunity structure where those with similar values are also more likely to meet one another (Feld, 1982). For example, to the extent that residency is segregated by class, race, ethnicity, and the like (outside the choice of any single individual), and to the 
extent that these same factors are associated with political views, it is likely that individuals with similar political views will be grouped together.

Homophily is not just imposed by structure and opportunity, but is also the result of endogenous factors. Similar individuals tend to attract each other, and (contrary to many a romantic comedy) opposites tend to repel. ${ }^{1}$ What Lazarsfeld and Merton (1954, p. 31) observed anecdotally, later empirical findings confirmed: given a choice, people will systematically choose those similar to themselves for relationships (Byrne, 1971).

There are a number of reasons for seeking out similar others. One is informational: Similar others offer relevant information (Festinger, 1954). For example, in seeking information about what movies to see, it is prudent to consult those with demonstrably similar taste. Another process is preferential: The social identity (Tajfel \& Turner, 1986) literature has focused on the consequences of in-group preference. Similar others are more likely to engage in cooperation, allowing the formation of stronger relationships (Buchan, Croson, \& Dawes, 2002). Dissimilarity entails greater competition, making the formation of strong relationships less likely (Nebus, 2006; Reagans, 2005).

A third motivator for affiliation with similar others is self-verification (Swann et al., 2000), the notion that people would prefer to interact with others who are likely to understand them as they understand themselves. This encourages sorting that would reinforce such understanding. A fourth reason is cognitive balance (e.g., Heider, 1958). Ties between individuals who hold dissimilar attitudes (including political views) are experienced as imbalanced. This imbalance causes discomfort. The imbalance may be resolved by dissolving the interpersonal relationship, or by one individual bringing his or her attitude into alignment with the other individual's. ${ }^{2}$ Importantly, such processes can operate outside of conscious awareness (Greenwald \& Banaji, 1995, p. 13). This tendency toward balanced relationships suggests that pairs of individuals who have consistent political orientations are relatively more likely to create and maintain relationships. These four processes provide the basis for our first hypothesis.

H1: Individuals will tend to have relationships with other individuals with similar political orientations.

As noted above, the opportunity structure for creating particular types of relationships makes a difference. For example, a liberal Democrat has fewer similar potential alters in Texas than Massachusetts. One outcome in such a scenario is that ego has to "settle" for relatively dissimilar alters. An alternative outcome is that ego will be relatively disengaged from the immediate milieu. For example, Newcomb (1943) found that in a relatively liberal milieu like Bennington College, conservative students had fewer ties than liberal students. Similarly, Finifter (1974) found that conservative union members had fewer attachments than liberal union members. These similar findings could be explained at the individual level by positing some intrinsic difference in the tie formation practices of liberal versus conservative individuals. A network-based or relational explanation is that those in the political minority of a social system will be relatively disengaged when faced with such an opportunity structure for relationships. Thus, our second hypothesis was as follows.

$H 2$ : In a majority liberal setting, conservatives will tend to be relatively less engaged in the network than liberals.

The configuration of an individual's friendships reflects some mix of the choices that individual makes (e.g., to talk with similar others) and factors exogenous to that individual (e.g., the types of individuals who happen to be near him or her). It is also possible, as discussed above, for the opportunity structure and endogenous choices to reinforce each 
other. Homophily notwithstanding, however, we know that our networks of political discussants are only imperfectly like us (Huckfeldt et al., 2002; Mutz, 2002), which, in turn, creates the possibility of social influence. ${ }^{3}$ In reality, the opportunity structure for forming relationships is often sharply constrained, as, for example, Mutz and Mondak (2006) explored empirically in the context of political interactions in the workplace.

\section{Network Effects: Social Influence}

Our networks, while dynamically evolving, are also simultaneously affecting us. A wellknown stream of social psychology and sociology research from the 1940s and 1950s (Newcomb, 1943; Lazarsfeld et al., 1948; Festinger et al., 1950; Festinger, 1954) explored how our networks affect our attitudes and behaviors. These findings were followed up by research in political science on contextual effects (Berelson, 1954; Putnam, 1966), as well as a series of studies using egocentric network data (Huckfeldt, Johnson, \& Sprague, 2002, 2004; Huckfeldt \& Sprague, 1987, 1991; Mutz, 2006). There is also a parallel, wholenetwork-oriented research vein in current sociological research, generally focusing on nonpolitical attitudes (e.g., Erickson, 1988; Friedkin, 1998, 2004; Friedkin \& Johnsen, 1997; Marsden \& Friedkin, 1993), as well as an emerging (or reemerging) thread of research in psychology (e.g., Levitan \& Visser, 2009).

All of these research streams suggest that there is a tendency for individuals to become more like their discussion partners over time. The theoretical underpinnings of attitudinal change include cognitive balance (e.g., Frank \& Fahrbach, 1999), group persuasion (Mackie \& Queller, 2000), and elite-driven models involving the dynamics of political attention (Zaller, 1992). ${ }^{4}$ The statement by an individual you know that he or she likes a movie sends you a signal that it is, indeed, a good movie, affecting your own belief about the movie. From a cognitive perspective, the statement by someone whom you like that he or she prefers a presidential candidate that you do not creates a tension that may be resolved by changing your own belief about that candidate. Not only is the friendship between two people endogenous, but so is the attachment between those individuals and their political views. Should a liberal talk to a conservative, they might choose not to become friends (or to sever an existing relationship), or one or both individuals might change their ideological orientation. This dynamic probably unfolds in an uneven, stochastic fashion. The equilibrium may evolve below the level of conscious adjustment (McConnell et al., 2008). Friendship begets familiarity, and familiarity (may) beget friendship, but what friends find out about each other is driven largely by the vagaries of conversations and events, and politics may not even come up. Presumably, in the absence of talk about politics, social influence on political views is limited or nonexistent.

Following from the work on cognitive balance, we hypothesize that valenced relationships-relationships that are emotionally and personally important, such as friendship - are likely to be a stronger source of social influence (Kenny, 1994) than taskbased relationships. Exposure to a particular viewpoint from someone you like will have a greater impact on your own opinion as compared to exposure to the same viewpoint from someone you work with. Thus, our third and fourth hypotheses were as follows.

H3: The political attitudes of people who have ties to each other will tend to become more similar over time.

H4: Social influence on political attitudes will be especially powerful among people who are friends, versus among people who work together. 


\section{Research Design}

\section{Analytical Challenge}

Because social similarity may generate both social ties and similar outcomes, including political attitudes, social similarity may be a source of a spurious causal association between social ties and attitudes. ${ }^{5}$ A critical challenge in studying the impact of social networks on political attitudes is dealing with this possible alternative explanation of a positive association between political behavior/attitudes and network configuration.

The problem of measuring social influence (associates affecting individuals) in the presence of selection effects (individuals choosing their associates) has been well documented in both the sociological (Mouw, 2006; Winship \& Mare, 1992) and the economic (Manski, 1993) literatures. A recent review (Soetevent, 2006) of efforts in economics to address this problem suggested three categories of strategies: (a) application of certain data collection procedures (e.g., manipulation via natural or laboratory experiments; Sacerdote, 2001), (b) use of inferential procedures that eliminate selection concerns (e.g., use of instrumental variables), and (c) direct evaluation of the functional form of the selection process (e.g., through a two-stage analysis).

Within political science, Nickerson (2008) offers a rare example of the first type of strategy for studying social contagion. Nickerson conducted an experimental study of the transmission of "get out the vote" messages within two-voter households by randomly manipulating the message that households received. Half of the households received a get out the vote message, and the other half a placebo message. The key finding was that, for households that received the get out the vote message, the individual in the household who did not answer the door was more likely to turn out (suggesting social transmission of the behavior). Huckfeldt, Sprague, and colleagues (Huckfeldt \& Sprague, 1987; Huckfeldt et al., 1993, 1995; Huckfeldt, Johnson, \& Sprague, 2002, 2004) followed a quasi-experimental path. They dealt with the coevolution of attitudes and networks in two ways: (a) by using extensive individual-level control variables and (b) by treating elections as an exogenous factor raising, for short periods, the salience of political views, thus activating political discussions and social influence processes.

This vein of research finds substantial evidence that people's political preferences become increasingly aligned with those of their contexts as an election nears. Yet, while these findings are compelling, they do not eliminate the possibility that the results are driven by divergent histories (e.g., campaign messages may differ depending on where you sit in the network) or a selection bias from omitted or difficult-to-measure factors such as associational choices (e.g., in Huckfeldt, Sprague, and colleagues' work, the reasons why an individual has a particular set of associates). ${ }^{6}$

We seek to advance this research through a longitudinal and more microscopic examination of social influence over time. Longitudinal data allow the examination of whether a difference in views between ego and alters today is associated with a convergence in attitudes tomorrow, avoiding some of the inferential challenges in discerning the difference between homophily and social influence in cross-sectional data. However, as Cohen-Cole and Fletcher (2008) highlight in their critique of Christakis and Fowler (2007), unobserved heterogeneity is still a concern with respect to longitudinal data, an issue we analyze in the discussion section in light of our findings (also see response by Fowler \& Christakis, 2008). ${ }^{7}$

Our research setting enables us to observe individuals' political views before and after exposure to one another. We can assume that initial political views are not the result of 
interactions with the other participants in the study. This assumption allows us to examine whether subsequent interactions among participants contribute to changes in their political views. This has an additional advantage that individuals likely accommodate themselves to differences with others over time. That is, it is plausible that one can observe disagreement in networks that results in neither persuasion nor reduction in communication (Lazer, 2001). The advantage of the research design here is that such a process of accommodation will not yet have taken place.

\section{Design and Data}

This study builds upon social network methods of assessing interpersonal social influence (Friedkin \& Johnsen, 2002; Leenders, 2002; Robins, Pattison, \& Elliott, 2001). Our data come from two originally distinct studies of the same cohort of 164 students entering a 2-year master's program in public policy. One study was longitudinal, surveying this cohort every semester of their program. This study provides our outcome variable: political attitude, measured at Time 1 (in the first couple of weeks of their first semester at school) and Time 3 (during the second semester of their first program year). A separate study surveyed the network structure of 161 members of this cohort ${ }^{8}$ at the beginning of the spring semester of their first year. This study provides the Time 2 data, collected in between the $\mathrm{T} 1$ and T3 surveys.

We integrate student responses from the three surveys. The T1 political attitudes survey provided 126 valid responses from 164 surveys (a response rate of 77\%). The T2 network survey provided 131 valid responses from 161 full-roster network surveys, a response rate of $81 \%$. The T3 political attitudes survey provided 104 valid responses from the 126 surveys, a response rate of $82.5 \%$. (In the longitudinal study, only students who completed the T1 survey were included in later surveys.)

The T1 and T3 political views of students were assessed via a 7-point Likert-type scale. Students were asked to place themselves on the political spectrum ranging from "extremely liberal" (1) to "extremely conservative" (7). ${ }^{9}$ Using the T2 network survey data, we measured two types of network ties: dyads mutually identifying each other as getting together socially and dyads mutually identifying each other as getting together for academic work. (A dyad is a pair of individuals in the system who may or may not have a tie.) Questions covering basic demographic and individual background data (sex, race, and religious affiliation) were included in the T1 survey. We also drew on institutional data regarding "section" assignment. The entire cohort of students was divided into three sections. Students in the same section took their "core" (required) classes together. Students were exogenously assigned to sections using a stratified assignment procedure that sought to achieve similar racial and gender compositions across the three sections. (See the Appendix for statistics showing that the sex, minority status, and religious group distributions were similar across the three sections.)

The T2 instrument was a network roster survey listing all students in that cohort by name and asking subjects to check the name "if you discussed academics (outside of the classroom) with him/her this year" (task ties) and "if you got together with him/her for non-academic reasons this year" (social ties).

Ninety students completed all three surveys and could be matched by individual student. The effective response rate over all three data collection periods yielded a sample comprising 55\% of the cohort surveyed. Although 55\% is the effective response rate for students whose responses could be matched across all three data collection periods, it is important to note that the response rate for the network survey alone exceeded the $80 \%$ response rate threshold commonly cited as necessary for generating useful insights into 
network structure from full-network surveys (e.g., Sparrowe et al., 2001, p. 319). There were no significant differences among any of the subsamples along any social category dimensions (see the Appendix). The overall distribution of political attitudes did not change significantly between the two time periods.

Our study design presents an unusual opportunity to disentangle the influence effects of social similarity from those of social network ties. The T1 measure of political attitudes occurs at the inception of the system. The $\mathrm{T} 1$ measure provides a preexposure baseline score that is not likely to be meaningfully influenced by interactions within the social system. This is important because it is probable that social systems are far more dynamic at their inception, and that in the long run people reach some type of accommodation between their network and attitudes somewhere short of perfect consonance between the two. That is, it is plausible that network effects may be significant but observable only for a short period. The T2 social network data reveal relationships emerging after that baseline. The T3 measure captures any changes in the outcome of interest. Evidence for social influence on political views is found in the significance of the association between a measure of the T1 political views of students' alters and their own T3 political views, controlling for each individual student's baseline political view as well as other individual and contextual effects. Any such significant association would represent the best and most unambiguous evidence thus far for direct social influence on political attitudes.

\section{Analysis}

Figure 1 provides a graphic image of our data. The nodes represent individuals, and the lines connecting nodes represent relationships (reciprocated social ties) among individuals. The shape of the node indicates which section the individual was assigned to (triangle $=$ section 1 , square $=$ section 2 , circle $=$ section 3 ). The shade of the node indicates the individual's initial political attitudes. Lighter nodes are more conservative and darker nodes are more liberal, with white and black nodes having the most extreme views. The size of the node reflects the direction of attitude change. Large shapes became more conservative, small shapes more liberal, and medium-sized nodes demonstrated no attitude change from T1 to T3.

Our central questions, expressed in terms of the imagery in Figure 1, can be restated as follows. First, is there segregation within the network based on political views? That is, are there more dark and more pale neighborhoods than one would expect by chance? Second, is there unambiguous evidence of social influence on political views? That is, did individuals in the darker (more liberal) neighborhoods of the network become even more liberal (depicted as smaller in size), and individuals in the paler neighborhoods even more conservative (depicted as larger in size)? Finally, were these effects more pronounced for social networks than for task networks? ${ }^{10}$

\section{Social Influence}

We first test for evidence that students influence one another's political views. The theory of network influence advanced by Huckfeldt and Sprague (1987) and their subsequent work with Johnson $(2002,2004)$ suggest that the views of one's alters in the aggregate are a potentially important source of network influence. Using the Time 2 network survey combined with the Time 1 survey of political views, we determined the Time 1 political views of all of ego's alters from both his or her social and task networks. Using these combined data, we constructed a set of two individual-level variables: (a) the mean Time 1 political view of ego's task-tied alters and (b) the mean Time 1 political view of ego's 


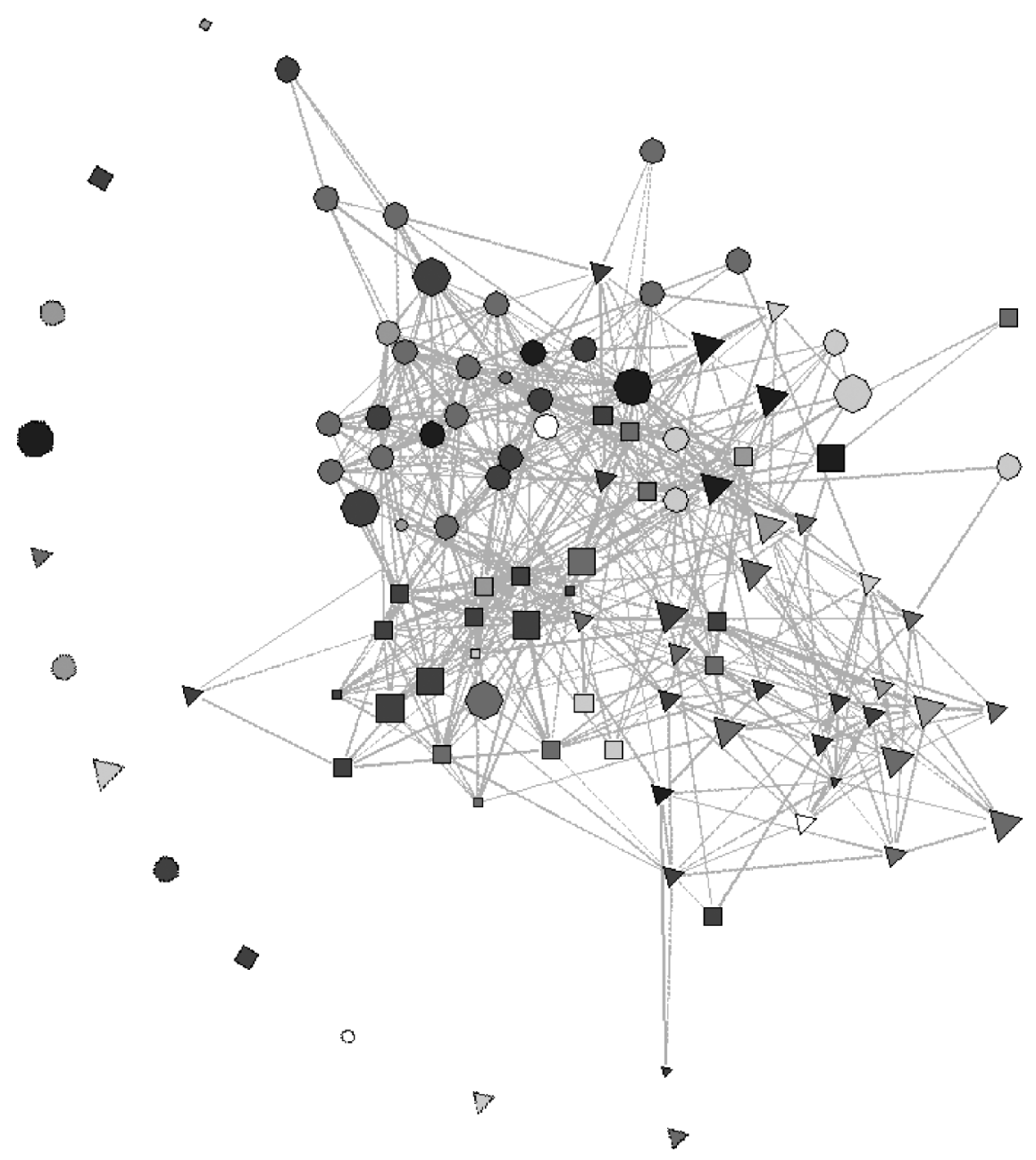

Figure 1. Friendship network and policy orientations of students (triangle = Section 1, square/ diamond $=$ Section 2 , circle $/$ octagon $=$ Section 3 ; black $=1$ [extremely liberal], white $=6$ [conservative] with 4 levels of gray distinguishing intermediate values; largest $=$ became more conservative, smallest $=$ became more liberal, medium size $=$ no change). For the purposes of this graph only, nodes with missing Time 3 political view are depicted as if they did not change their views (i.e., depicted as having medium size).

socially tied alters. The means, standard deviations, and correlations between these two variables along with ego's Time 1 and Time 3 political views are provided in the Appendix.

Our initial tests for social influence on political views estimate whether ego's selfselected social environment is significantly associated with his or her Time 3 political views, controlling for his or her Time 1 political views (considered a preexposure measure of political view) and a set of demographic and institutional controls. Because our dependent variable in this analysis, students' Time 3 political attitudes, comes from responses to a 7-point Likert-type survey question, we use ordered logit regression models ${ }^{11}$ to estimate our regression coefficients and their standard errors (Agresti, 2002). The results of these tests are presented in Table 1. In Table 1, Models 1 through 4 examine the determinants of Time 3 political views. We include Time 1 political views, which 
should capture any individual-level drivers of Time 3 political views. In these models, significant effects of the demographic variables indicate that particular demographic groups show changes in political views between Time 1 and Time 3. Model 1 indicates significant associations for the sex variable, "men," and for the race/ethnicity category "Asian," suggesting that women and students identifying as Asian are more likely to become more conservative as compared to men and Whites, respectively. ${ }^{12}$

\section{Table 1}

Ordered logit models predicting Time 3 political views based on demographic characteristics, section assignment, and Time 1 views of alters

\begin{tabular}{ccccc}
\hline & Model 1 & Model 2 & Model 3 & Model 4 \\
\hline Male & $-1.27^{* *}$ & $-1.29^{*}$ & $-1.37^{*}$ & $-1.37^{*}$ \\
& $(0.47)$ & $(0.52)$ & $(0.54)$ & $(0.55)$
\end{tabular}

Religious affiliation (Referent: Protestant)

\begin{tabular}{lcccc} 
Catholic & -1.21 & $-1.65^{*}$ & $-1.48^{\dagger}$ & $-1.49^{\dagger}$ \\
\multirow{3}{*}{ Jewish } & $(0.77)$ & $(0.84)$ & $(0.88)$ & $(0.88)$ \\
& -0.51 & -0.58 & -0.51 & -0.51 \\
\multirow{3}{*}{ Other } & $(0.71)$ & $(0.79)$ & $(0.81)$ & $(0.81)$ \\
& -0.71 & -1.08 & -0.41 & -0.44 \\
\multirow{2}{*}{ None } & $(0.93)$ & $(0.96)$ & $(0.93)$ & $(0.95)$ \\
& -0.89 & $-1.28^{\dagger}$ & $-1.18^{\dagger}$ & $-1.19^{\dagger}$ \\
& $(0.59)$ & $(0.66)$ & $(0.67)$ & $(0.67)$
\end{tabular}

Race/Ethnicity (Referent: White)

$\begin{array}{lcccc}\text { Black } & 0.06 & 0.89 & 1.31 & 1.31 \\ & (0.85) & (0.98) & (1.05) & (1.05) \\ \text { Latino } & 0.51 & 1.08 & 1.90 & 1.86 \\ & (1.06) & (1.32) & (1.41) & (1.43) \\ \text { Native American } & -1.24 & -1.33 & -1.11 & -1.10 \\ & (1.85) & (1.95) & (2.02) & (2.02) \\ \text { Asian } & 1.87^{*} & 1.82^{*} & 2.04^{*} & 2.04^{*} \\ & (0.73) & (0.87) & (0.84) & (0.85) \\ \text { Other/Missing } & -0.50 & -0.55 & -1.18 & -1.17 \\ & (0.83) & (0.92) & (0.96) & (0.96)\end{array}$

Section (Referent: Section 3 )

$\begin{array}{lcccc}\text { Section } 1 & 0.73 & 0.86 & 0.51 & 0.53 \\ & (0.52) & (0.58) & (0.58) & (0.59) \\ \text { Section } 2 & -0.33 & -0.36 & -0.35 & -0.34 \\ & (0.59) & (0.62) & (0.65) & (0.66)\end{array}$

Time 1 political view

$\begin{array}{llll}2.40^{* * *} & 2.59^{* * *} & 2.93^{* * *} & 2.92^{* * *} \\ (0.34) & (0.39) & (0.44) & (0.44)\end{array}$

Mean of academic alters' 
Table 1

Continued

\begin{tabular}{lcccc}
\hline & Model 1 & Model 2 & Model 3 & Model 4 \\
\hline $\begin{array}{l}\text { Mean of social alters' T1 } \\
\quad \text { view }\end{array}$ & & & $\begin{array}{c}3.16^{* * *} \\
(0.76)\end{array}$ & $\begin{array}{c}3.08^{* *} \\
(0.98)\end{array}$ \\
$\begin{array}{l}\text { Cut-points } \\
\text { 1 to 2 }\end{array}$ & & & \\
2 to 3 & 1.63 & 6.40 & 10.62 & 10.72 \\
3 to 4 & 4.59 & 9.60 & 14.18 & 14.28 \\
4 to 5 & 7.31 & 12.63 & 17.41 & 17.51 \\
5 to 6 & 9.88 & 15.42 & 20.85 & 20.94 \\
Log-likelihood & 13.57 & 19.79 & 26.44 & 26.50 \\
Pseudo $R^{2}$ & -89.0 & -75.4 & -68.6 & -68.6 \\
\hline
\end{tabular}

Note. Standard errors are in parentheses.

${ }^{\dagger} p<.10 ;{ }^{*} p<.05 ;{ }^{* *} p<.01 ;{ }^{* * *} p<.001$.

In Models 2 through 4 in Table 1, we add in the social influence indicators. The mean Time 1 political views of both task and social alters have positive significant effects on students' changing political views. The more conservative an ego's alters' Time 1 views are, the more conservative ego will be at Time 3. Similarly, the more liberal an ego's alters' Time 1 views are, the more liberal ego will be at Time 3. Although this relationship is true for alters in both task and social networks, Model 4 shows that it is the social network alters that are more influential. When terms for task network alters and social network alters are included in the same model (as in Model 4 in Table 1), only the mean T1 view of socially tied alters remains a significant predictor of Time 3 views. ${ }^{13}$

These findings provide support for $\mathrm{H} 3$ and $\mathrm{H} 4$. That is, we find strong and consistent evidence of social influence with respect to ideological self-ratings. These effects are substantively quite large. Table 2 offers a summary of the size of these effects at around the

Table 2

Illustrative interpretation of social influence findings with actual data ranges indicated

\begin{tabular}{|c|c|c|c|c|c|c|c|c|}
\hline \multirow[b]{2}{*}{ Ego's Time 1 political view } & \multicolumn{6}{|c|}{ Mean Time 1 view of socially tied alters } & \multicolumn{2}{|c|}{ Data range } \\
\hline & 1 & 2 & 3 & 4 & 5 & 6 & Min & $\operatorname{Max}$ \\
\hline 1 & 1.01 & 1.14 & 1.73 & 2.54 & 3.38 & 4.24 & 2.00 & 3.29 \\
\hline 2 & 1.14 & 1.73 & 2.54 & 3.38 & 4.23 & 4.96 & 1.50 & 3.29 \\
\hline 3 & 1.73 & 2.53 & 3.38 & 4.23 & 4.96 & 5.59 & 2.00 & 3.50 \\
\hline 4 & 2.53 & 3.38 & 4.23 & 4.96 & 5.58 & 5.95 & 2.36 & 3.31 \\
\hline 5 & 3.38 & 4.23 & 4.96 & 5.58 & 5.95 & 6.00 & 2.38 & 3.83 \\
\hline 6 & 4.23 & 4.95 & 5.58 & 5.95 & 6.00 & 6.00 & 2.45 & 2.78 \\
\hline
\end{tabular}

Note. Results are based on predicted estimates from an ordered logit regression model of the following form: $\mathrm{T} 3$ view $=\mathrm{f}$ ( $\mathrm{T} 1$ view, mean of social alters' $\mathrm{T} 1$ view, section dummies) (i.e., Model 2 from Table 3 but ignoring demographic distinctiveness). The referent section (Section 3 ) is also assumed. 
mean of the various control variables. We find that the typical marginal effect of a single point change in average $\mathrm{T} 1$ attitude of $\mathrm{T} 2$ alters is associated with approximately a .6 to .8 point shift in ego's view by T3.

As an additional test that social ties are the key mechanism for attitude change, we divide the potential relational pathways of influence on an individual into three categories of dyads: dyad type 1 (individuals to whom ego has a social tie), dyad type 2 (individuals to whom ego has a task tie), and dyad type 3 (individuals to whom ego has both social and task ties). Does having a task tie to someone in addition to a social tie increase his or her influence on ego? Table 3 duplicates the four models in Table 1, adding, as an independent variable, the mean views of individuals to whom ego has both task and social ties (i.e., "type 3" dyad alters).

Table 3

Testing social influence effects from alters with both social and task ties versus all task tied and all socially tied alters

\begin{tabular}{ccccc}
\hline & Model 1 & Model 2 & Model 3 & Model 4 \\
\hline Male & $-1.25^{*}$ & $-1.25^{*}$ & $-1.44^{* *}$ & $-1.42^{*}$ \\
& $(0.53)$ & $(0.53)$ & $(0.55)$ & $(0.56)$
\end{tabular}

Religious affiliation (Referent: Protestant)

\begin{tabular}{lcccc} 
Catholic & $-1.56^{\dagger}$ & $-1.57^{\dagger}$ & -1.43 & -1.44 \\
& $(0.85)$ & $(0.85)$ & $(0.89)$ & $(0.89)$ \\
Jewish & -0.78 & -0.77 & -0.38 & -0.30 \\
& $(0.80)$ & $(0.80)$ & $(0.82)$ & $(0.83)$ \\
\multirow{2}{*}{ Other } & -0.68 & -0.73 & -0.33 & -0.47 \\
& $(0.93)$ & $(0.95)$ & $(0.93)$ & $(0.95)$ \\
\multirow{2}{*}{ None } & $-1.11^{\dagger}$ & $-1.12^{\dagger}$ & $-1.19^{\dagger}$ & $-1.24^{\dagger}$ \\
& $(0.67)$ & $(0.67)$ & $(0.66)$ & $(0.67)$
\end{tabular}

Race/Ethnicity (Referent: White)

$\begin{array}{lcccc}\text { Black } & 1.13 & 1.14 & 1.27 & 1.28 \\ & (1.02) & (1.02) & (1.06) & (1.06) \\ \text { Latino } & 1.43 & 1.37 & 2.06 & 1.92 \\ & (1.36) & (1.37) & (1.44) & (1.44) \\ \text { Native } & -1.50 & -1.47 & -0.95 & -0.78 \\ \text { American } & (1.96) & (1.97) & (2.03) & (2.04) \\ \text { Asian } & 1.52^{\dagger} & 1.55^{\dagger} & 2.25^{*} & 2.43^{* *} \\ & (0.85) & (0.86) & (0.88) & (0.92) \\ \text { Other/Missing } & -0.91 & -0.88 & -1.21 & -1.14 \\ & (0.93) & (0.94) & (0.96) & (0.96)\end{array}$

Section (Referent: Section 3)

\begin{tabular}{lcccc} 
Section 1 & 0.57 & 0.60 & 0.52 & 0.65 \\
& $(0.58)$ & $(0.60)$ & $(0.58)$ & $(0.60)$ \\
Section 2 & -0.56 & -0.52 & -0.21 & -0.05 \\
& $(0.65)$ & $(0.67)$ & $(0.68)$ & $(0.70)$ \\
\hline
\end{tabular}


Table 3

Continued

\begin{tabular}{lcccc}
\hline & Model 1 & Model 2 & Model 3 & Model 4 \\
\hline Time 1 political & $2.72^{* * *}$ & $2.72^{* * *}$ & $2.97^{* * *}$ & $2.98^{* * *}$ \\
$\quad$ view & $(0.42)$ & $(0.42)$ & $(0.45)$ & $(0.45)$ \\
Mean T1 view of & $1.92^{* *}$ & $1.74^{\dagger}$ & -0.97 & -1.81 \\
$\quad$ type 3 dyad alters & $(0.57)$ & $(0.90)$ & $(1.18)$ & $(1.55)$ \\
Mean T1 view of & & 0.27 & & 0.99 \\
$\quad$ task alters & & $(1.10)$ & & $(0.89)$ \\
Mean T1 view of & & & $4.30^{* *}$ & $4.61^{* *}$ \\
$\quad$ social alters & & & $(1.59)$ & $(1.65)$ \\
Cut-points & & & & \\
1 to 2 & 6.95 & 7.23 & 11.22 & 12.53 \\
2 to 3 & 10.25 & 10.53 & 14.81 & 16.19 \\
3 to 4 & 13.31 & 13.61 & 18.05 & 19.45 \\
4 to 5 & 16.49 & 16.77 & 21.52 & 22.87 \\
5 to 6 & 21.44 & 21.66 & 27.25 & 28.42 \\
Log-likelihood & -72.1 & -72.0 & -68.3 & -67.9 \\
\hline
\end{tabular}

Standard errors are in parentheses.

${ }^{\dagger} p<.10 ;{ }^{*} p<.05 ;{ }^{* *} p<.01 ;{ }^{* * *} p<.001$.

The negative coefficient for dual ties in Model 4 of Table 3 indicates that the marginal effect of having a task tie in addition to a social tie with an individual is unlikely to be significantly positive. This suggests that, consistent with and providing additional support for $\mathrm{H} 4$, the pathway of influence on political attitudes is through social (rather than task) ties.

\section{Network Formation}

To test for political view homophily, we look for evidence that the ties measured at Time 2 are significantly associated with dyadic similarities in Time 1 political views. Figure 1 offers some hints as to the key drivers of the emergent network. There are clearly more ties within cohort (i.e., shape of node), while it is not so clear whether ties cluster by political preference (i.e., lightness or darkness). There is only a weakly significant correlation between ego's T1 political views and the mean T1 political views of ego's socially tied alters (see the Appendix). Figure 2 plots the latter as a function of the former, showing no visibly strong association. If there were perfect ideological homophily (i.e., students talk only to students with the same political views), Figure 2 would be a line with a slope of 1 . More generally, if there were significant attitude homophily, we would expect an obvious positive slope. Given the near-zero slope apparent in Figure 2, it is clear that if there is any political view homophily, it is weak at best.

A second way to assess political view homophily is using network density measures. A density measure is simply the ratio of actual ties to potential ties. For example, if there are 5 actual ties out of a set of 10 possible ties, the density would be 0.5 . Tie density is a first-order estimate of tie probability. Here, we look at the odds ratio of the densities (probabilities) of within-group ties and between-group ties, where "group" refers to those 


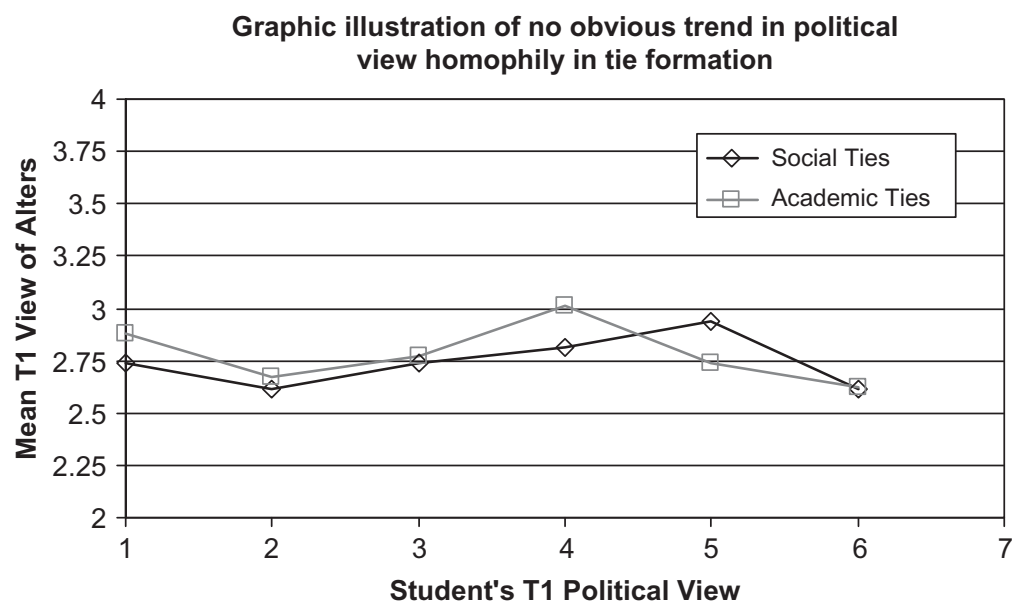

Figure 2. Political view of ego plotted against average views of alters.

similar on some dimension-demographic or attitudinal. In the absence of homophily, the odds ratio would be 1 (i.e., just as likely to form a within-group tie as a between-group tie). If there is homophily, the ratio would be greater than 1 , and if there is heterophily, the ratio would be less than 1 . Table 4 presents these calculated densities and associated odds ratios for political views, as well as for other known sources of homophily: sex, race,

\section{Table 4}

Densities and odds ratios of ties within and between categories

\begin{tabular}{lcc}
\hline Grouping category & Social tie density (\%) & Odds ratio \\
\hline Political views & & 1.20 \\
Same view & 11.7 & \\
Different view (All) & 9.9 & \\
Differ by 1 & 11.3 & \\
Differ by 2 & 9.4 & \\
Differ by 3 & 6.4 & \\
Differ by 4 & 10.2 & 1.06 \\
Differ by 5 & 3.7 & \\
Sex & 10.7 & 2.28 \\
Within-group & 10.1 & \\
Between-group & & \\
Race & 14.8 & 1.48 \\
Within-group & 7.1 & \\
Between-group & & \\
Religion & 13.4 & \\
Within-group & 9.4 & \\
Between-group & & \\
Section & 21.3 & \\
Within-group & 5.0 & \\
Between-group & & \\
\hline
\end{tabular}

Note. Data are based on ties among 105 individuals, or 5,460 dyads. 
religion (Marsden, 1988), and section membership. As Table 4 shows, the odds of forming a tie with a person of the same political view are 1.2 times the odds of forming a tie with a person of a different political view, suggesting that there is a mild tendency toward political homophily. As with the correlation statistic, this finding is consistent with the presence of political view homophily. These findings are only suggestive, however, because there are multiple interrelated factors (e.g., political views and religion) that are correlated with the presence/absence of a tie.

A complication in a multivariate analysis of dyadic data is that the observations are typically interdependent, thus violating a fundamental assumption of many statistical methods. For example, it is a well-established finding in the study of social networks (Wasserman \& Faust, 1994) that triads tend to be closed. In a social system of three people $\mathrm{A}, \mathrm{B}$, and $\mathrm{C}$, if $\mathrm{A}$ is tied to $\mathrm{B}$ and $\mathrm{B}$ is tied to $\mathrm{C}, \mathrm{A}$ and $\mathrm{C}$ are more likely to have a tie (to "close" the triangle) than in the system where B is absent. In addition, whenever such a "triangle" forms, the ties among A, B, and C are more likely to survive over time than ties in dyads without a third shared partner (for a detailed discussion of both phenomena, see Krackhardt \& Handcock, 2007, and for interactions with homophily, see Louch, 2000).

In testing for associations between network properties and tie formation likelihoods, there are two classes of statistical approaches: the multiple regression quadratic assignment procedure (MRQAP) and exponential random graph models (ERGM, also called " $p$ *" models). MRQAP is designed for testing the significance of the relationship between different dyad-level variables - for example, comparing different networks or whether (in the extant case) dyadic similarity along various dimensions predicts the presence of a relationship. ERGM allows testing for the presence of dyad-level associations, but also the presence of particular structural tendencies in the network (such as the tendency for triad closure). Here our primary objective is to examine the relationship between dyadlevel variables (whether the similarity in Time 1 political views between two individuals is associated with the likelihood that those two individuals share a tie at Time 2), so either method of estimation is appropriate. We therefore report our findings using both approaches (Table 5). ${ }^{14}$

In these analyses, the key term of interest is the absolute value of the difference in Time 1 political views. This variable is a distance measure. The larger the value, the more dissimilar the individuals are in terms of political views. A negative coefficient for this variable would suggest that homophily in political views contributes to tie formation; the smaller the difference in political views between two people, the more likely they are to form a tie. A positive coefficient on this variable would suggest heterophily; dissimilar individuals are more likely to form ties. Among the models shown in Table 5 where significance levels could be estimated, all revealed the identical pattern of significance for the homophily-related terms: similarities in section assignment, race, and religion are strongly associated with increases in the likelihood of having a tie at Time 2. Neither differences in Time 1 political views nor sex similarities were associated with tie probabilities. The sum of Time 1 political views had a significant negative association with tie probabilities. This means that the larger the dyadic sum of Time 1 political views (i.e., the more conservative the dyad), the less likely the dyad has a tie at Time 2 . The smaller the dyadic sum of Time 1 political views (i.e., the more liberal the dyad), the more likely the dyad has a tie at Time 2. Figure 3 shows that even for the two ERG models for which significance levels could not be estimated, the patterns of estimated homophily-related coefficients are quite similar to the model where significance levels could be estimated. ${ }^{15}$ Table 6 provides a substantive interpretation of our homophily findings by demonstrating how various differences affect relative tie probabilities. 


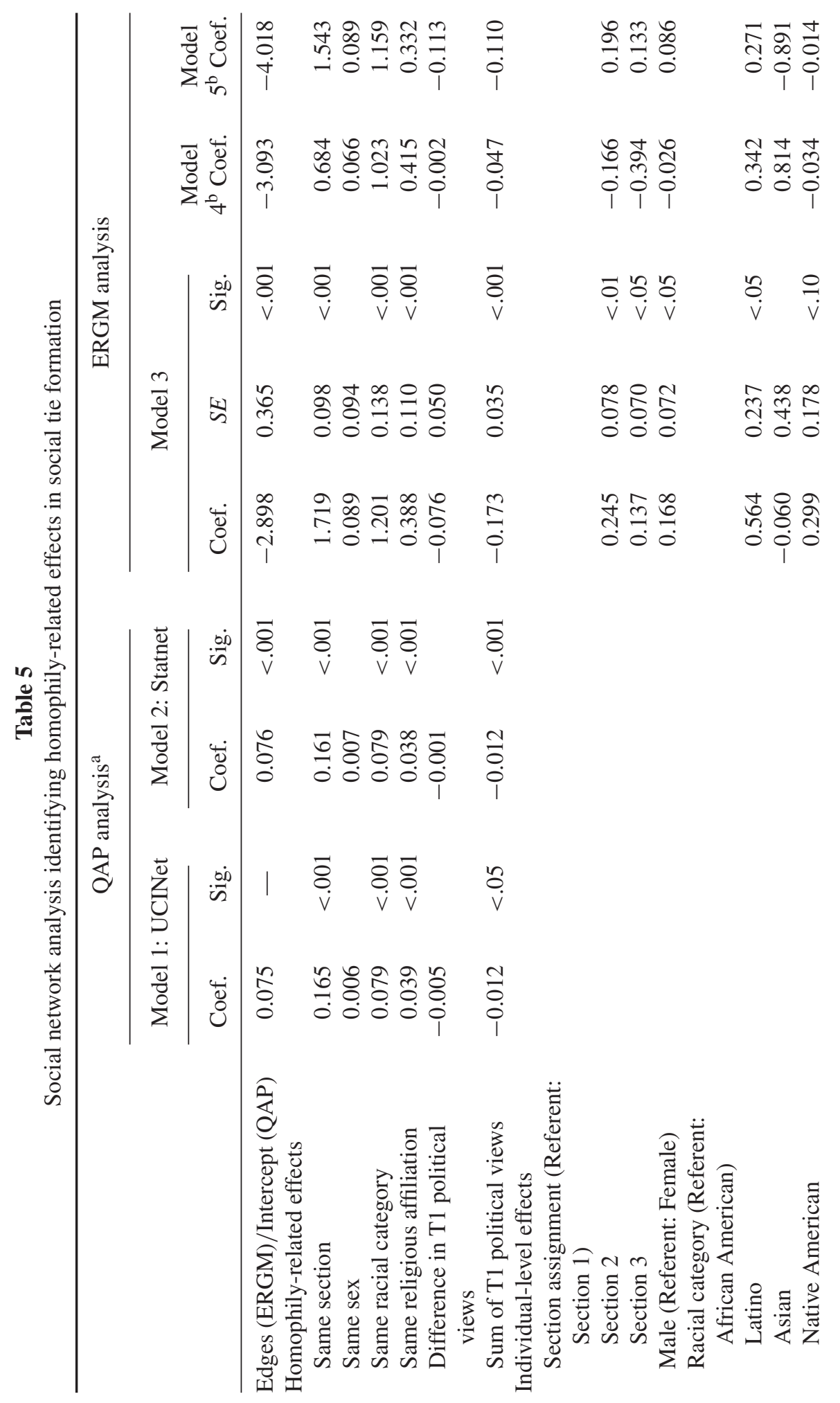




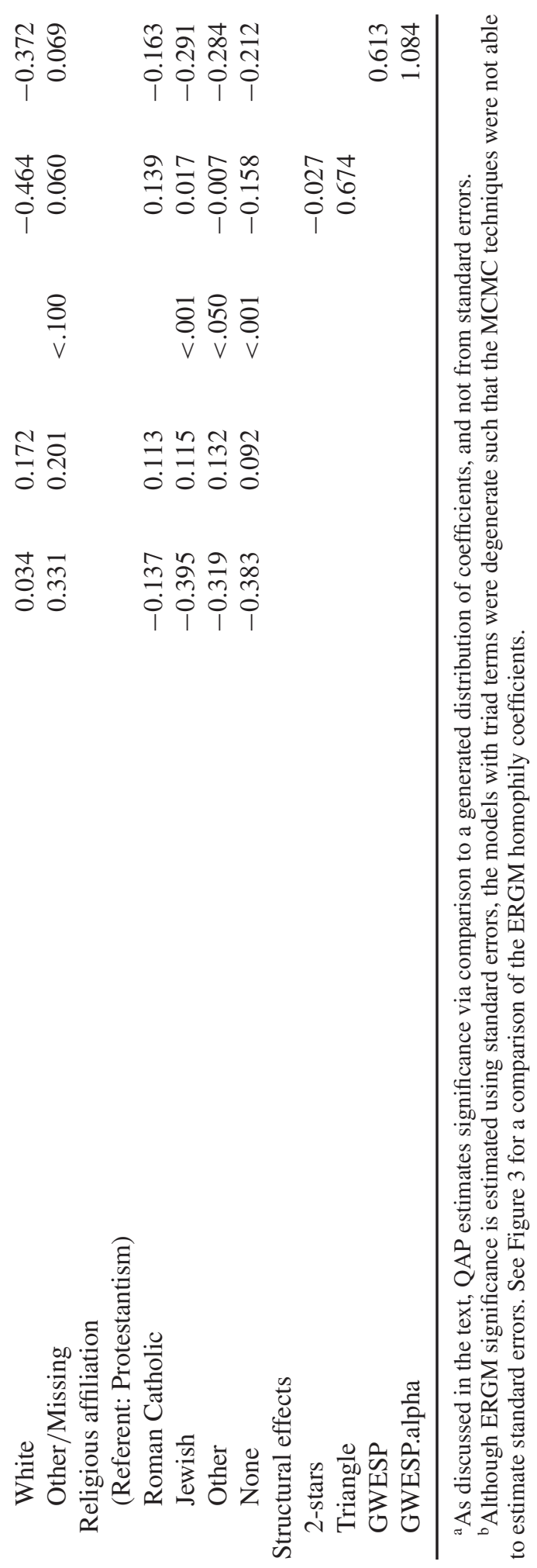




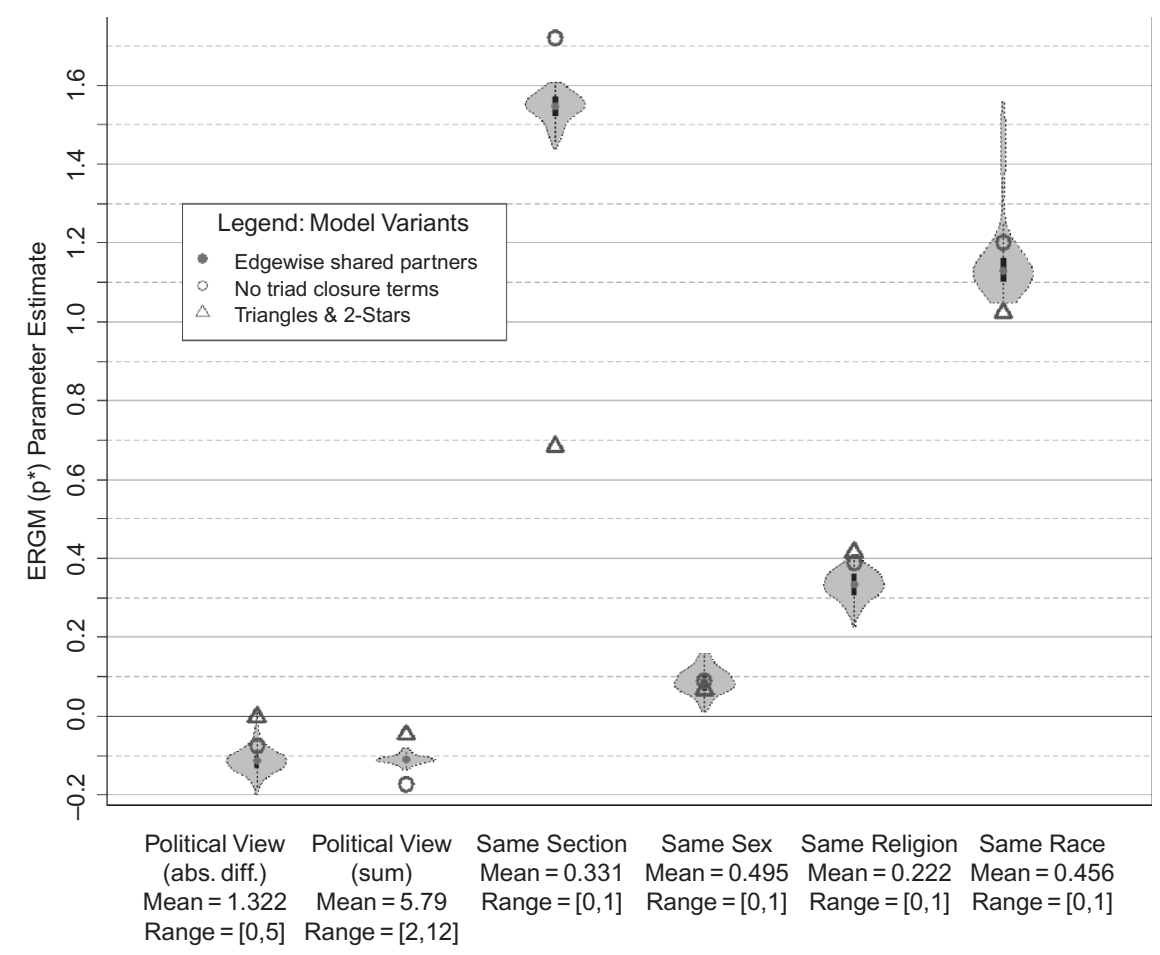

Figure 3. Comparison of ERGM estimated homophily-related coefficients. The edgewise shared partner coefficients yield a distribution because of the simultaneous estimation of the geometric weighting parameter, alpha. The coefficient distributions are plotted as a violin plot (Hintze \& Nelson, 1998) combining the information of a box plot with the frequency distribution of the underlying data.

Our analysis generated several surprising findings. First, we find no evidence of political view homophily in social tie formation (H1). We can see that even for a dyad with a difference in political views of 2 full points on a 7-point scale, the relative tie probability is comparable to that for an opposite-sex dyad. (Our data show no significant homophily by sex.) We do not infer from this finding that political view homophily does not exist. Rather, political view similarity was not an important determinant of tie formation in this setting. (It may be that the relatively low degree of variation in political views diminished the importance of this dimension in tie formation relative to what would occur in a more politically heterogeneous setting.) Another surprise is the sheer magnitude of racial and religious homophily in this cosmopolitan, university setting. Two individuals who are the same race and religion are about six times more likely to form a friendship than two individuals who are different on those two dimensions.

We do find support for $\mathrm{H} 2$, with the significant negative association between the dyadic sum of Time 1 political views and tie probability. That is, liberals are more likely to form ties (and conservatives are less likely to form ties) in this setting. We examine this last finding in more detail below. 
Table 6

Illustration of the impact of dissimilarity on the relative probability of formation of a social tie

\begin{tabular}{lc}
\hline & Relative probability \\
\hline $\begin{array}{l}\text { 1. Dyad between someone of the modal profile and another modal } \\
\text { profile individual }\end{array}$ & 1 \\
& \\
Dyad between someone of the modal profile and one who is & \\
otherwise the same as the modal profile but differs in the & \\
following: & 0.93 \\
2. Absolute difference in T1 political views $=1$ & 0.86 \\
3. Absolute difference in T1 political views $=2$ & 0.80 \\
4. Absolute difference in T1 political views $=3$ & 0.13 \\
5. Section membership & 0.87 \\
6. Sex & 0.18 \\
7. Racial category & 0.65 \\
8. Religious affiliation & 0.12 \\
9. Both sex and racial category & 0.57 \\
10. Both sex and religious affiliation & 0.16 \\
11. Both racial category and religious affiliation & 0.10 \\
12. Sex, racial category, and religious affiliation & \\
\hline
\end{tabular}

Note. Calculations are based on the parameter estimates from Model 3 in Table 7. Odds ratios are for tie probabilities for the dyads relative to a dyad composed of two completely similar nodes (both modal profiles: female, White, Protestants in Section 3 with T1 political views $=3$ ). For example, the odds ratio for a social tie with respect to different section membership (0.13) means that the probability of a friendship forming between two people not in the same section is $13 \%$ that of the probability of a friendship forming between two in the same section.

\section{Politics and Networking}

Are there different levels of social network engagement across the political spectrum? The ERGM above suggested that conservatives are more peripheral than liberals in this population. Here we further examine this relationship. Table 7 summarizes the relationship between political orientation and two measures of centrality: degree (the number of ties an individual has) and betweenness (the number of times an individual lies on the shortest path between all other pairs of individuals; see Freeman, 1979).

Individuals on the left of the political spectrum are significantly more central $(p<.05)$ by both measures of centrality. For example, they have 50\% more ties than those on the right. There is no tendency for conservatives ( 5 or 6 on the Likert scale) to talk to each other. For example, the tie density (the ratio of observed ties to all possible ties, a firstorder estimate of tie probability) of conservative-conservative social ties is $6.8 \%$, and that of task ties is $5.7 \%$, smaller than the tie density of conservative-liberal ties, $7.1 \%$ (social) and $9.0 \%$ (task). As a point of comparison, the tie density of liberal-liberal ties is $12.1 \%$ (social) and $12.8 \%$ (task). The conservative minority, rather than banding together, connected less with each other and less with the network in general. This is a notable contrast to demographic minorities within the school, such as African Americans, Jews, and Hispanics, who generally did not have fewer ties and had a tendency to form in-group ties. 
Table 7

Association between political orientation and network centrality

\begin{tabular}{lccr}
\hline $\begin{array}{l}\text { Ego's Time 1 } \\
\text { political view }\end{array}$ & $\begin{array}{c}\text { Mean }(S D) \text { degree centrality } \\
\text { of ego in social-tie network }\end{array}$ & $\begin{array}{c}\text { Mean }(S D) \text { betweenness centrality } \\
\text { of ego in social-tie network }\end{array}$ & $N$ \\
\hline 1 & $11.6(8.3)$ & $1.4(1.27)$ & 9 \\
2 & $12.0(6.9)$ & $1.1(1.01)$ & 36 \\
3 & $11.2(7.0)$ & $0.93(1.12)$ & 35 \\
4 & $9.6(7.2)$ & $0.82(0.87)$ & 10 \\
5 & $7.6(5.9)$ & $0.52(0.74)$ & 3 \\
6 & $6.7(5.9)$ & $0.40(0.37)$ & \\
Correlation with & $-.207^{*}$ & $-.243^{*}$ & \\
$\quad$ T1 view & & & \\
\hline
\end{tabular}

${ }^{*} p<.05$.

This conservative disengagement could be a reaction to being a particular kind of minority in this setting (e.g., being a conservative at a liberal policy school), or could reflect some intrinsic difference about the social networking priorities and/or proclivities of liberals and conservatives. We have data to address the last explanation from our Time 1 survey. Students were asked to identify their top 2 reasons from a list of 11 possible reasons for enrolling in that particular graduate school of public policy. One option was the "value of social connections for my career." This variable was coded as either 1 (among the student's top 2 reasons) or 0 . The mean was 0.18 and the standard deviation was 0.38 $(n=119)$. Students were also asked to rank the top 3 ways from a list of 5 possible ways they expected the policy school to contribute to their professional lives. One option was "contacts-the people I meet at and through the school will be helpful to me in my future career." This variable was coded as 3 (contacts as the most important way), 2 (contacts as the second most important way), 1 (contacts as the third most important way), or 0 (contacts as either fourth or fifth in importance). The mean was 1.02, and the standard deviation was $0.90(n=122)$. Correlations between these two variables and students' Time 1 political views are -.03 and .04 , respectively. Neither correlation is significant. This ex post analysis does not support the conjecture that political view is associated with social networking attitudes or intentions.

\section{Discussion}

This article provides powerful evidence for social influence affecting political attitudes. The longitudinal nature of the data accounts for the coevolutionary complexities in assessing social influence. As a result, our findings are robust to concerns about selection and endogeneity. The potential for environmental confounders (Cohen-Cole \& Fletcher, 2008) would require omitted factors that (we think implausibly in this case) satisfy two criteria: (a) The process must be associated with changes in political views, and (b) the process must push individuals toward the selection of alters who lean in the same direction that their political views will change.

This finding is all the more striking given the population under study, which consisted of elites that one would anticipate had crystallized opinions. There is an implicit assumption in much of the literature on public opinion that elites are likely immune from social 
influence. While caution needs to be exercised in extrapolating from this particular group, these results also suggest that this assumption needs to be reexamined with a critical eye.

We also found that the pathway to social influence seems to be through social rather than task-based ties. This finding is particularly notable for our population because political views were certainly conveyed through task relationships. Our findings suggest that persuasion might be more a function of affect than information transfer, and persuasion is unlikely to be a function merely of interaction frequency. They also suggest that persuasion is not simply a reflection of opinion leadership, with contagion following expertise (Katz \& Lazarsfeld, 1955), although a direct examination is not possible in the absence of measures of expertise in this population. The finding regarding social ties is of special importance, given research that suggests that a disproportionate share of discordant political communication occurs in the workplace (Mutz \& Mondak, 2006). These results suggest that these workplace ties may result in relatively little persuasion.

We found only weak, and in the end, nonsignificant tendencies toward political homophily. By comparison, the effects of race/ethnicity and religion on network formation were orders of magnitude larger. It is possible that this lack of homophily reflects the overarching environment of an educational institution, which in principle emphasizes the value of differences in opinion in enabling discourse, although one might expect that politics would be a powerful social divide because of the high salience of politics in a policy school. Instead, what we found was that the political minority, rather than sticking together, essentially withdrew from the community. That is, rather than a "red-blue" divide within this population, there is a blue (majority) core and a red (minority) periphery. The relative peripherality of conservatives is consistent with previous studies where conservatives were in the minority (Finifter, 1974; Newcomb, 1943), although we do not find, as Finifter did, that the political conservatives tend to band together.

The magnitude of homophily with respect to race, ethnicity, and religion was a surprise. Our expectation was that in the immersive experience of professional school, with an ideology that emphasizes the value of diversity and powerful institutional forces (such as assigned sections and assigned core courses) pushing dissimilar people together, race/ethnicity and religion would not be quite such strong predictors of who created ties with whom. Instead, we found that patterns endemic in the broader society (e.g., Marsden, 1987) replicated themselves in this microcosm.

Methodologically, this article builds a bridge among three different traditions in the study of social influence: the controlled, laboratory experimental approach of social psychology; the whole-network tradition of sociology; and the ego-centric network orientation of political science. Our findings are thus complementary to those of Huckfeldt, Sprague, and colleagues (Huckfeldt \& Sprague, 1987; Huckfeldt et al., 1993, 1995; Huckfeldt, Johnson, \& Sprague, 2002, 2004; see also Campus et al., 2008) regarding the power of social relationships in shaping politics, providing some of the micro-underpinnings of the processes that Huckfeldt and colleagues examine. From this union of traditions, literatures, and methodological approaches, we have crafted a demonstration of the importance of social influence in determining political attitudes. Furthermore, we introduced to the political science literature two powerful methods for the statistical analysis of social network data: MRQAP and ERGM.

Our study took place in a very particular setting, and one could argue that the particularities of the setting limit the generalizability of our findings. In response to such criticism, we first acknowledge that we have sacrificed breadth for depth. While we have offered strong evidence of social influence on political attitudes, this confidence applies solely to our empirical setting. Still, we argue that there exists no ideally generalizable setting for the 
study of social influence. Instead, we assert that society is made up of many diverse micro settings, which vary along dimensions that affect social influence processes. Indeed, much of the study of social capital focuses on the emergent outcomes from different micro-level processes of network evolution. For example, Bourdieu (1986) found that small ethnic minorities have a great in-group capacity to regulate behavior because of the difficulty of exiting that network. Similarly, we argue, social influence is an emergent property of microlevel processes governing the coevolution of individuals and their attitudes. The conceptual challenges around connecting micro-level processes and macro-level outcomes have long been identified as fundamental in political science (see Eulau, 1969; Schelling, 1978). We offer here a new approach to traversing the chasm between micro-level social processes (i.e., selection and influence) underlying the attitudes of individuals and the macro-level patterns (the distribution of the attitudes and patterns of communication in a population) that result.

We acknowledge the limitations to the generalizability of this particular setting. We chose the setting because we were seeking a robust test of social influence with respect to political attitudes. To this end, we wanted a setting where (a) we could capture political attitudes prior to exposure to others in the system, (b) individuals would be exposed to novel perspectives, and (c) political views were likely to be both expressed and socially salient. The first year of a master's in public policy program fit those criteria perfectly. Of course, there are other settings where politics are rarely discussed, and thus there is perhaps less social influence (although we would note that this was a population where individuals began with fairly strong and perhaps less malleable opinions). We do not claim that social influence of political views typically operates with the strength we identified in this study. Rather, we present these findings first as an existential proof of social influence and second as a sharper examination of the pathways (social rather than task) through which that influence flows.

\section{Notes}

1. There is a continuum between the exogenous and endogenous drivers of the tendency for similars to form relationships, as Schelling's (1978) classic work on segregation illustrates. Schelling found that weak preferences to be grouped with similar others lead to an opportunity structure where most individuals can communicate only with similar others.

2. Note that this literature is cognitive in nature (i.e., about ego's beliefs) and, thus, does not necessarily imply that if ego is liberal and alter conservative they will not be friends. It suggests that ego might (incorrectly) believe that alter is liberal, allowing the friendship to endure; that ego might believe alter is conservative, making an enduring friendship less likely; or that ego might classify alter as an exceptional type of conservative more simpatico with liberal beliefs than other conservatives (Heider, 1958, p. 208).

3. While virtually all research on the topic indicates that there is homophily in our discussion networks, there is disagreement as to whether near-perfect homogeneity is typical (e.g., cf. Huckfeldt, Johnson, and Sprague, 2004, p. 19, and Huckfeldt, Mendez, \& Osborn, 2004, p. 72, to Mutz, 2006, p. 38).

4. Klofstad (2007), in his examination of the social determinants of political behavior, offers several mechanisms that mediate the effects of behavioral contagion in the case of civic engagement, where alters might provide information that facilitates engagement, influence the motivation to become engaged, or (most importantly) directly recruit the ego to become involved.

5. As an example, one empirical investigation into the role of contacts in finding jobs that explicitly explored this potential spurious association found that ties among individuals can capture social similarity, which drives similar employment outcomes (Mouw, 2003). 
6. Our design has some similarities to Klofstad (2007), who examined whether roommates affected each other's level of civic engagement, where there were preexposure measures of civic engagement and political discussions among roommates were associated with increased levels of engagement. However, contagion was not directly examined because the level of engagement of the roommates was not captured.

7. The particular innovation of Christakis and Fowler (2007) was the use of the direction of the tie in identification of possible causal effects; that is, influence was found when A named B but not when B named A.

8. The network survey was administered to only 161 of the initial 164 students because 3 students from the initial cohort did not take the required core spring semester class.

9. There were no extreme conservatives (ranking of 7) observed in the sample.

10. This question references $\mathrm{H} 4$. We note that our empirical setting presents a conservative test for this hypothesis. We expect in general that friendship ties are more likely to be the conduits for social influence of political attitudes than task-based ties. As we noted, this influence is contingent on political topics coming up in interactions within the friendship. Among these public policy students, a dyad sharing a task-based tie assuredly has discussed political topics, and we have no such assurance for friendships.

11. Ordered regression models produce "cut-point" estimates for the transition between levels of the dependent variable. Because these cut points are distinct for each model estimation, the magnitudes of the estimated coefficients themselves are not meaningful when compared across models. Only the sign of the coefficients and their level of significance may be meaningfully compared across models.

12. As an additional test of the robustness of our findings, we replicated our analyses with Asians removed from the sample. There were no substantive changes to our social influence estimates. We also looked for significant differences in social influence between men and women, and found none. Analyses are available upon request.

13. Although the mean $\mathrm{T} 1$ views of social and task alters are significantly correlated, the variance-inflated factors associated with Model 4 for these two terms are 2.03 and 1.93, respectively. Both factors are well below the common threshold of 10 as an indicator of multicollinearity issues (e.g., Myers, 1990, p. 369).

14. In the Appendix, we discuss these two statistical approaches in greater detail.

15. If triad closure and survival amplify apparent homophily, we would expect the ERGM without triad terms to overestimate homophily effects. Thus, the triad terms should reduce the significance of homophily terms, making it highly unlikely that political attitude homophily would plausibly emerge as significant in these two models. Again, the QAP model estimates hold constant the structural properties of the network.

\section{References}

Agresti, A. (2002). Categorical data (2nd ed.). New York: Wiley.

Berelson, B. (1954). Voting: A study of opinion formation in a presidential campaign. Chicago: University of Chicago Press.

Borgatti, S. P., Everett, M. G., \& Freeman, L. C. (2002). UCINet for Windows: Software for social network analysis. Cambridge, MA: Analytic Technologies.

Bourdieu, P. (1986). The forms of capital. In J. G. Richardson (Ed.), Handbook of theory and research for the sociology of education (pp. 241-258). New York: Greenwood Press.

Buchan, N. R., Croson, R., \& Dawes, R. (2002). Swift neighbors and persistent strangers: A crosscultural investigation of trust and reciprocity in social exchange. American Journal of Sociology, 108, 168-206.

Byrne, D. (1971). The attraction paradigm. New York: Academic Press.

Campus, D., Pasquino, G., \& Vaccari, C. (2008). Social networks, political discussion, and voting in Italy: A study of the 2006 election. Political Communication, 25, 423-444. 
Christakis, N., \& Fowler, J. (2007). The spread of obesity in a large social network over 32 years. New England Journal of Medicine, 357, 370-379.

Cohen-Cole, E., \& Fletcher, J. (2008). Detecting implausible social network effects in acne, height, and headaches: Longitudinal analysis. British Medical Journal, 337, a2533.

Dekker, D., Krackhardt, D., \& Snijders, T. A. B. (2007). Sensitivity of MRQAP tests to collinearity and autocorrelation conditions. Psychometrika, 72, 563-581.

Erickson, B. H. (1988). The relational basis of attitudes. In B. Wellman \& S. D. Berkowitz (Eds.), Social structures: A network approach (pp. 99-122). Cambridge, UK: Cambridge University Press.

Eulau, H. (1969). Micro-macro political analysis: Accents of inquiry. Chicago: Aldine.

Feld, S. L. (1982). Social structural determinants of similarity among associates. American Sociological Review, 47, 797-801.

Festinger, L. (1954). A theory of social comparison processes. Human Relations, 7, 117-140.

Festinger, L., Schachter, S., Back, K., Bauer, C., \& Kennedy, R. (1950). Social pressures in informal groups: A study of human factors in housing. New York: Harper.

Finifter, A. W. (1974). The friendship group as a protective environment for political deviants. American Political Science Review, 68, 607-625.

Fowler, J., \& Christakis, N. (2008). Estimating peer effects on health in social networks: A response to Cohen-Cole and Fletcher and Trogdon, Nonnemaker, and Pais. Journal of Health Economics, $27,1400-1405$.

Frank, K. A., \& Fahrbach, K. (1999). Organizational culture as a complex system: Balance and information in models of influence and selection. Organization Science, 10, 253-277.

Freeman, L. C. (1979). Centrality in social networks I: Conceptual clarification. Social Networks, 1, 215-239.

Friedkin, N. E. (1998). A structural theory of social influence: Structural analysis in the social sciences. Cambridge, UK: Cambridge University Press.

Friedkin, N. E. (2004). Social cohesion. Annual Review of Sociology, 30, 409-425.

Friedkin, N. E., \& Johnsen, E. (1997). Social positions in influence networks. Social Networks, 19, 209-222.

Friedkin, N. E., \& Johnsen, E. (2002). Control loss and Fayol's gangplanks. Social Networks, 24, 395-406.

Goodreau, S., Handcock, M., Hunter, D., Butts, C., \& Morris, M. (2008). A statnet tutorial. Journal of Statistical Software, 24, 1-26.

Greenwald, A. M., \& Banaji, M. (1995). Implicit social cognition: Attitudes, self-esteem, and stereotypes. Psychological Review, 102, 4-27.

Habermas, J. (1996). Between facts and norms: Contributions to a discourse theory of law and democracy (W. Rehg, Trans.). Cambridge, MA: MIT Press.

Handcock, M. S., Hunter, D. R., Butts, C. T., Goodreau, S. M., \& Morris, M. (2003). Statnet: Software tools for the statistical modeling of network data. Retrieved from http://statnetproject.org.

Heider, F. (1958). Social perception and phenomenal causality. Psychological Review, 51, 358-374.

Hintze, J. L., \& Nelson, R. D. (1998). Violin plots: A box plot-density trace synergism. American Statistician, 52, 181-184.

Holland, P. W., \& Leinhardt, S. (1981). An exponential family of probability distributions for directed graphs. Journal of the American Statistical Association, 76, 33-50.

Huckfeldt, R., Johnson, P., \& Sprague, J. (2002). Political environments, political dynamics, and the survival of disagreement. Journal of Politics, 64, 1-21.

Huckfeldt, R., Johnson, P., \& Sprague, J. (2004). Political disagreement: The survival of diverse opinions within communication networks. Cambridge, UK: Cambridge University Press.

Huckfeldt, R., Mendez, J., \& Osborn, T. (2004). Disagreement, ambivalence, and engagement: The political consequences of heterogeneous networks. Political Psychology, 25, 65-95.

Huckfeldt, R., Plutzer, E., \& Sprague, J. (1993). Alternative contexts of political behavior: Churches, neighborhoods, and individuals. Journal of Politics, 55, 365-381. 
Huckfeldt, R., \& Sprague, J. (1987. Networks in context-The social flow of political information. American Political Science Review, 81, 1197-1216.

Huckfeldt, R., \& Sprague, J. (1991). Discussant effects on vote choice-Intimacy, structure, and interdependence. Journal of Politics, 53, 122-158.

Huckfeldt, R., \& Sprague, J. (1995). Citizens, politics, and social communication. New York: Cambridge University Press.

Hunter, D. R. (2007). Curved exponential family models for social networks. Social Networks, 29, 216-230.

Ikeda, K., \& Huckfeldt, R. (2001). Political communication and disagreement among citizens in Japan and the United States. Political Behavior, 23, 23-52.

Katz, E., \& Lazarsfeld, P. (1955). Personal influence. New York: The Free Press.

Kenny, C. B. (1994). The microenvironment of attitude change. Journal of Politics, 56, 715-728.

Kenny, C. B. (1998). The behavioral consequences of political discussion: Another look at discussant effects on vote choice. Journal of Politics, 60, 231-244.

Klofstad, C. A. (2007). Talk leads to recruitment: How discussions about politics and current events increase civic participation. Political Research Quarterly, 60, 180-191.

Krackhardt, D. (1988). Predicting with networks-Nonparametric multiple regression analysis of dyadic data. Social Networks, 10, 359-381.

Krackhardt, D., \& Handcock, M. S. (2007). Heider vs. Simmel: Emergent features in dynamic structures. Lecture Notes in Computer Science, 4503, 14-27.

Lazarsfeld, P., Berelson, B., \& Gaudet, H. (1948). The people's choice: How the voter makes up his mind in a presidential campaign (2nd ed.). New York: Columbia University Press.

Lazarsfeld, P., \& Merton, R. (1954). Friendship as social process: A substantive and methodological analysis. In P. L. Kendall (Ed.), The varied sociology of Paul Lazarsfeld (pp. 298-348). New York: Columbia University Press.

Lazer, D. (2001). The coevolution of individual and network. The Journal of Mathematical Sociology, 25, 69-108.

Leenders, R. (2002). Modeling social influence through network autocorrelation: Constructing the weight matrix. Social Networks, 24, 21-47.

Levitan, L., \& Visser, P. (2009). Social network composition and attitude strength: Exploring the dynamics within newly formed social networks. Journal of Experimental Social Psychology, 45, 1057-1067.

Louch, H. (2000). Personal network integration: Transitivity and homophily in strong-tie relations. Social Networks, 22, 45-64.

Mackie, D. M., \& Queller, S. (2000). The impact of group membership on persuasion: Revisiting "who says what to whom with what effect?" In D. A. Terry \& M. A. Hogg (Eds.), Attitudes, behavior, and social context: The role of norms and group membership (pp. 135-156). Mahwah, NJ: Erlbaum.

Mansbridge, J. (1999). Everyday talk in the deliberative system. In S. Macedo (Ed.), Deliberative politics: Essays on democracy and disagreement (pp. 211-239). Oxford, UK: Oxford University Press.

Manski, C. F. (1993). Identification of endogenous social effects: The reflection problem. Review of Economic Studies, 60, 531-542.

Marsden, P. V. (1987). Core discussion networks of Americans. American Sociological Review, 52, $122-131$.

Marsden, P. V. (1988). Homogeneity in confiding relations. Social Networks, 10, 57-76.

Marsden, P. V., \& Friedkin, N. (1993). Network studies of social influence. Sociological Methods \& Research, 22, 127-151.

McConnell, A. R., Rydell, R. J., Strain, L. M., \& Mackie, D. M. (2008). Forming implicit and explicit attitudes toward individuals: Social group association cues. Journal of Personality and Social Psychology, 94, 792-807. 
McPherson, M., Smith-Lovin, L., \& Cook, J. (2001). Birds of a feather: Homophily in social networks. Annual Review of Sociology, 27, 415-444.

Morris, M., Handcock, M., \& Hunter, D. (2008). Specification of exponential family random graph models: Terms and computational aspects. Journal of Statistical Software, 24, 1-24.

Mouw, T. (2003). Social capital and finding a job: Do contacts matter? American Sociological Review, 68, 868-898.

Mouw, T. (2006). Estimating the causal effect of social capital: A review of recent research. Annual Review of Sociology, 32, 79-102.

Mutz, D. C. (2002). Cross-cutting social networks: Testing democratic theory in practice. American Political Science Review, 96, 111-126.

Mutz, D. C. (2006). Hearing the other side: Deliberative versus participatory democracy. Cambridge, UK: Cambridge University Press.

Mutz, D. C., \& Mondak, J. (2006). The workplace as a context for cross-cutting political discourse. Journal of Politics, 68, 140-155.

Myers, R. (1990). Classical and modern regression with applications (2nd ed.). Boston: Duxbury Press.

Nebus, J. (2006). Building collegial information networks: A theory of advice network generation. Academy of Management Review, 31, 615-637.

Newcomb, T. M. (1943). Personality and social change: Attitude formation in a student community. New York: Dryden Press.

Newcomb, T. M. (1961). The acquaintance process. New York: Holt, Rinehart \& Winston.

Nickerson, D. (2008). Is voting contagious? Evidence from two field experiments. American Political Science Review, 102, 49-57.

Putnam, R. (1966). Political attitudes and the local community. American Political Science Review, 60, 640-654.

Reagans, R. (2005). Preferences, identity, and competition: Predicting tie strength from demographic data. Management Science, 51, 1374-1383.

Robins, G., Pattison, P., \& Elliott, P. (2001). Network models for social influence processes. Psychometrika, 66, 161-189.

Sacerdote, B. (2001). Peer effects with random assignment: Results for Dartmouth roommates. Quarterly Journal of Economics, 116, 681-704.

Schelling, T. (1978). Micromotives and macrobehavior. New York: Norton.

Snijders, T., Pattison, P., Robins, G., \& Handcock, M. (2006). New specifications for exponential random graph models. Sociological Methodology, 36, 99-153.

Soetevent, A. R. (2006). Empirics of the identification of social interactions: An evaluation of the approaches and their results. Journal of Economic Surveys, 20, 193-228.

Sparrowe, R. T., Liden, R., Wayne, S., \& Kraimer, M. (2001). Social networks and the performance of individuals and groups. Academy of Management Journal, 44, 316-325.

Swann, W. B., Jr., Milton, L. P., \& Polzer, J. T. (2000). Should we create a niche or fall in line? Identity negotiation and small group effectiveness. Journal of Personality and Social Psychology, 79, 238-250.

Tajfel, H., \& Turner, J. (1986). The social identity theory of intergroup behavior. In W. G. Austin \& S. Worchel (Eds.) Psychology of intergroup relations (pp. 7-24). Chicago: Nelson-Hall.

Verbrugge, L. (1977). The structure of adult friendship choices. Social Forces, 56, 576-597.

Wasserman, S., \& Faust, K. (1994). Social network analysis: Methods and applications. Cambridge, UK: Cambridge University Press.

Wasserman, S., \& Pattison, P. (1996). Logit models and logistic regressions for social networks: I. An introduction to Markov graphs and $\mathrm{p}^{*}$. Psychometrika, 61, 401-452.

Winship, C., \& Mare, R. (1992). Models for sample selection bias. Annual Review of Sociology, 18, 327-350.

Zaller, J. R. (1992). The nature and origin of mass opinion. Cambridge, UK: Cambridge University Press. 


\section{Appendix A: Summary Statistics for and Correlations Among Political Orientation Variables}

\begin{tabular}{lccccccc}
\hline & $M$ & $S D$ & $N$ & 1 & 2 & 3 & 4 \\
\hline 1. T1 political view & 2.90 & 1.22 & 105 & - & $0.772^{* * *}$ & 0.047 & $0.181^{\dagger}$ \\
2. T3 political view & 3.09 & 1.24 & 90 & & - & $0.241^{*}$ & $0.439^{* * *}$ \\
3. Mean of task alters' T1 views & 2.76 & 0.39 & 96 & & & - & $0.587^{* * *}$ \\
4. Mean of social alters' T1 views & 2.72 & 0.38 & 93 & & & & - \\
\hline
\end{tabular}

${ }^{\dagger} p<.10 ;{ }^{*} p<.05 ;{ }^{* * *} p<.001$.

\section{Appendix B: QAP and ERGM}

The QAP approach (Krackhardt, 1988) estimates regression model coefficients and then uses random permutations of the network data to generate a distribution of coefficient estimates from random networks with the same structure. The actual estimates are then compared with this generated distribution to test for significance. Improvements in this procedure have been made to ensure conservative estimation of standard errors across less-than-ideally structured data (Dekker, Krackhardt, \& Snijders 2007). We used the multiple regression version of QAP with these improvements as implemented in both UCINet (Borgatti, Everett, \& Freeman, 2002) and the R package statnet (Handcock et al., 2003). Our QAP models include parameters for estimating the homophily effects of sex, race, religion, and section membership as well as political view dissimilarities (using the absolute value of the difference between a pair of individuals' T1 political views) and the absolute political view of the dyad (using the sum of T1 political views of a pair of individuals as twice the mean view of the dyad).

The statistics of the ERGM approach (Holland \& Leinhardt, 1981; Snijders et al., 2006) are summarized as follows (Goodreau et al., 2008, p. 8). The probability of observing a set of network edges (and non-edges) is given by:

$$
\mathrm{P}(\mathrm{Y}=\mathrm{y} \mid \mathrm{X})=\exp \left[\Theta^{\mathrm{T}} \mathrm{g}(\mathrm{y}, \mathrm{X})\right] / \kappa(\Theta),
$$

where $\mathrm{Y}$ is a random set of edges and non-edges, $\mathrm{y}$ is a specific set of edges and non-edges, $\mathrm{X}$ is a matrix of attributes on the vertices, $\mathrm{g}(\mathrm{y}, \mathrm{X})$ constitutes a vector of network statistics, $\Theta$ is the vector of coefficients, and $\kappa(\Theta)$ is a constant that normalizes the term. The model can also be expressed equivalently as stipulating the log-odds that any edge will be present holding constant the rest of the network configuration as:

$$
\operatorname{logit}\left(\mathrm{Y}_{\mathrm{ij}}=1\right)=\Theta^{\mathrm{T}} \delta[\mathrm{g}(\mathrm{y}, \mathrm{X})]_{\mathrm{ij}},
$$

where $\mathrm{Y}_{\mathrm{ij}}$ is a pair of actors in $\mathrm{Y}$ and $\delta[\mathrm{g}(\mathrm{y}, \mathrm{X})]_{\mathrm{ij}}$ is the change in $\mathrm{g}(\mathrm{y}, \mathrm{X})$ when $\mathrm{y}_{\mathrm{ij}}$ moves from 0 to 1 .

In addition to the terms in our MRQAP model, our ERGM must include individualspecific terms ${ }^{\ddagger}$ and terms to account for structural effects. There are a number of ways to

QAP preserves the structure of the similarity-matrix predictors, which, in turn, preserves the representation of the different demographic categories and section composition. ERGM is based on random graphs, so composition terms must be explicitly represented for accurate estimates of homophily. (For example, in a system with two groups, mostly reds and a few greens, most ties will be red-red as a result of composition, not homophily.) 
model triad effects within an ERGM (Hunter, 2007; Morris, Handcock \& Hunter 2008). We used and report on three such approaches: (a) no triad terms, (b) a statistic for a count of triangles and a statistic for a count of "2-stars" (unclosed triangles), and (c) a statistic based on the number of edgewise shared partners of a dyad (Hunter, 2007). ${ }^{\S}$ In the absence of triad terms (i.e. approach [1]), the standard errors can be estimated directly. In the presence of triad terms, Markov Chain Monte Carlo (MCMC) estimation techniques are necessary.

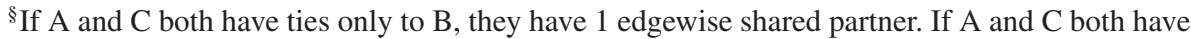
ties to $\mathrm{B}$ and D, they have two edgewise shared partners, and so on. Having more edgewise shared partners is likely to increase the likelihood of forming a tie, but this increase is unlikely to be linear. In our model, the effect is geometrically weighted with the weighting parameter-alpha—estimated directly from the data. As a result, this model has a term-GWESP-for the geometrically weighted edgewise shared partner, and an estimation of the weighting term-GWESP.alpha. 